Oral presentation

Open Access

\title{
What patients' characteristics predict outcome? Stefan Priebe
}

\author{
Address: Unit for Social and Community Psychiatry, Queen Mary, University of London, Academic Unit, Newham Center for Mental Health, \\ Cherry Tree Way, Glen Road, London, E13 8SP, UK \\ from WPA Thematic Conference. Coercive Treatment in Psychiatry: A Comprehensive Review \\ Dresden, Germany. 6-8 June 2007 \\ Published: 19 December 2007 \\ BMC Psychiatry 2007, 7(SuppI I):S78 doi:I0.I I86/I47I-244X-7-SI-S78
}

This abstract is available from: http://www.biomedcentral.com/I47I-244X/7/SI/S78

(c) 2007 Priebe; licensee BioMed Central Ltd.

The study 'Outcomes of Involuntary Hospital Admission in England' was linked to EUNOMIA and presents the largest ever national study on outcomes and predictors for outcomes of involuntary hospital admission. Patients were assessed within the first week after admission, after four weeks, three months and twelve months. More than 800 patients were interviewed after admission. Baseline and outcome data was obtained also for those patients who for various reasons did not participate in interviews. This paper summarises what patient characteristics predict outcome in terms of clinical improvement, readmissions and patients' retrospective assessment as to whether the admission was justified and the treatment beneficial. The findings show that studies based on participants only can lead to biased findings. 